\title{
Eagle's Syndrome - View from the General Practitioners Perspective
}

\author{
Daminee Chickooree $^{1, *}$, Vahsish Ram $^{2}$ \\ ${ }^{1}$ BDS, MDS Oral and Maxillofacial Surgery, The second Xiangya hospital of Central South University, Renmin road, no 139, Changsha, \\ Hunan, 410011, China \\ ${ }^{2}$ BDS, MDS Conservative and Endodontics, The first Xiangya hospital of Central South University, Changsha, Hunan, 410011, China
}

\begin{abstract}
Eagle's syndrome, the famous discovery of W. Eagle, is associated with repeated episodes of pain on rotating the neck, dysphagia and referred otalgia due to elongation of styloid process or ossified stylohyoid. Familiarity with Eagle's syndrome shows that its symptoms can be easily confused with other craniomandibular diseases. Since it is a rare clinical entity, its diagnosis is often hard to make, especially in the absence of sound clinical knowledge and good radiographs. Depending on the position of styloid process in relation to underlying anatomical structures, symptoms vary considerably, and in severe cases continuous compression of the carotid artery can lead to stroke and even death. The treatment of choice is mainly styloidectomy; however some conservative treatment is still being practiced. Very few studies have been reported in the literature classifying the elongation and calcification patterns of styloid process. In this review we aim to spread light on the epidemiology, clinical manifestation, diagnosis, and therapy for Eagle's syndrome and also target to help the general practitioner in differential diagnosis with other conditions that can provide similar signs and symptoms.
\end{abstract}

Keywords Styloid process, Eagle's syndrome, Stylohyoid ligament, Stylo-carotid artery syndrome

\section{Introduction}

Eagle's syndrome, also known as elongated styloid process, is a rare clinical entity that may be the cause of craniofacial and cervical pain. It is still little known among dentists. [1] It consists of anatomical changes in the styloid process, which can lead to clinical signs and symptoms such as pain in the TMJ or preauricular region, none specific cervical pain, limited or asymmetric mandibular movements, earaches, headaches, tinnitus, earaches, vertigo/dizziness, feeling of ear fullness, hypoacusis, hyperacusis, odynophagia and foreign body sensation in the throat. $[2,3]$ Symptoms vary from foreign body in the throat perception to stroke and even sudden death. [4] Most clinicians have no experience in this diagnosis and ultimately attribute the symptoms to other causes. Wrong diagnosis ultimately hampers treatment success. In this retrospective study, our main aim is to find out what are the main reasons for late diagnosis of this condition in modern practice? Does experience play an important role in identifying Eagle's syndrome condition? Why do most of the practitioners miss this condition and how can we prevent such events?

\section{Methodology}

* Corresponding author:

drdaminee@gmail.com (Daminee Chickooree)

Published online at http://journal.sapub.org/cmd

Copyright (C) 2014 Scientific \& Academic Publishing. All Rights Reserved
Data were gleaned from a literature search of available medical and dental databases including science direct, Research gate, Ovid, PubMed, Medline, Cochrane, Scopus and Google Scholar. The search phrases included the main set "Eagle's syndrome" with defined subsets such as "stylo-carotid artery syndrome" clinical signs and symptoms, radiographic investigations", diagnosis" and "treatment modalities". The inclusion criteria were from Jan 2001- Feb 2014. The review was limited to English-language articles. Because of its rare occurrence, all cases were included regardless of age, sex or ethnicity. About 3,230 and 286 articles have been indexed respectively in the science direct database and PubMed.

\section{History and Epidemiology}

Literature revealed that in 1652, Pietro Marchetti identified an elongated styloid process related to an ossifying process of the stylohyoid ligament. However, it was Watt W. Eagle, in 1937, that first defined Eagle's syndrome as an arbitrary entity related to elongation of styloid process or to mineralization of the stylohyoid ligament complex and divided it into two subtypes: the "classic syndrome" and the "stylo-carotid artery syndrome." [5, 6] The classic styloid process syndrome is due to fibrous tissue causing distortion of the cranial nerve endings in the tonsillar bed after tonsillectomy and includes sensation of foreign body in throat and pain on deglutition and in the throat. It frequently follows tonsillectomy. The other type, stylocarotid syndrome, 
is not correlated to tonsillectomy and is due to compression of sympathetic chain in carotid sheath by the ossified ligament or tip of the styloid process, resulting in an incessant pain irradiating in the carotid zone. [5-7]

The average length of the styloid process is individually variable, but in most of the patients, it usually ranges from $20 \mathrm{~mm}$ to $30 \mathrm{~mm}$. [6] The styloid process length, which is more than $30 \mathrm{~mm}$, was considered to be elongated. $[5,6]$ Another interesting finding in the literature is that only a small percentage of population (about $4 \%$ ) is believed to have an elongated styloid process and not all of them are actually symptomatic; in fact symptoms has been noted in only about $4-10 \%$ of them. [7] Hence, elongated styloid process is not pathognomonic for Eagle's syndrome as many patients with inadvertent findings of an elongated styloid process are asymptomatic.

The epidemiological incidence of Eagle's syndrome is variable in the literature; however it is usually seen in adult patients aged 30 to 50 years. Nevertheless, a few suspicious cases in children have also been reported. [8] No statistically significant association between age and elongation-calcifica tion patterns has been reported till now $[9,10]$ Also, there is no significant sex predilection in the occurrence of mineralization of the styloid process; but some authors reported that symptoms are more common in females. Literatures are not in agreement with sexual dimorphism of Eagle's syndrome $[9,11]$.

\subsection{Anatomical Consideration}

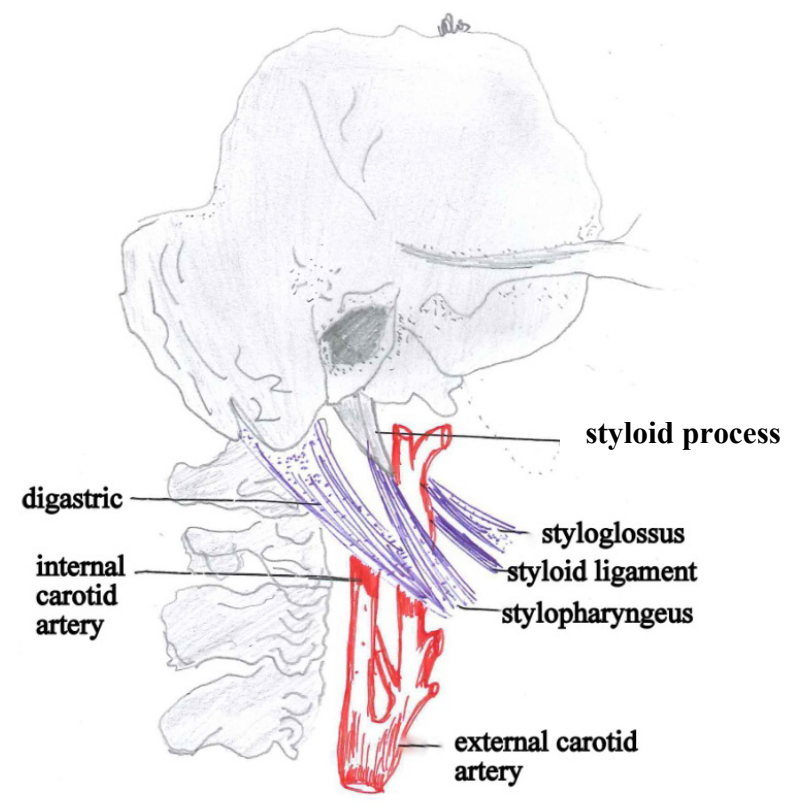

Figure 1. The relationship of the styloid process to its surrounding structures

Anatomically, styloid process is a slender, elongated and cylindrical bony projection which originates from temporal bone and lies anteriorly to the mastoid process, between the internal and external carotid arteries, and laterally to the tonsillar fossa. [12] The styloid process provides two ligament attachments which are the stylohyoid and stylomandibular ligaments and three muscles which are the stylopharyngeus, stylohyoid and styloglossus. [13] Medial to it are the superior pharyngeal constrictor muscle and pharyngobasilar fascia, the internal jugular vein and the accessory, hypoglossal, vagus, and glossopharyngeal nerves. The stylohyoid ligament connects the styloid process with the small cornus of the hyoid bone. (Fig 1) The apex of the styloid process is clinically important because it is located between internal and external carotid arteries and significant elongation may lead to compression of the sympathetic chain in carotid sheath. $[12,13]$

\subsection{Clinical Manifestations}

The hallmark of Eagle's syndrome is the typical dull and nagging pain of the elongated styloid process that becomes worse during deglutition and can be reproduced by palpation of the tonsillar fossa. [14] Symptoms which are produced due to elongated styloid process or pressure on neurovascular structures include pharyngodynia, dysphagia, foreign body sensation in pharynx, otalgia, headache, pain on neck rotation, and facial pain. Duration of patients' symptoms ranged from 8 months to 37 months (mean, 14 months). Patients exhibiting signs and symptoms like migraines, cluster headaches, or transient neurological symptoms caused by irritation of the periarterial sympathetic nerve plexus overlying the carotid artery, were classified as having the carotid artery syndrome. [15] The neurosurgical literature reveals that Eagle's syndrome has also been associated with transient ischemic attack in a patient presenting with severe reversible narrowing of the internal carotid artery on head movement to the affected side. [15] A broad diversity of symptoms have been attributed to elongation of the styloid process and since these symptoms are non-specific, they can be easily mixed up with other disorders such as aerodigestive tract malignancies, neuralgia, temporomandibular joint dysfunction (TMD), dental malocclusion, and hyoid bursitis [1].

\subsection{Etiopathology}

Variation is the law of nature. Although it is reported that elongation of the styloid process and ossification of the stylohyoid ligament are more likely to cause Eagle's syndrome, the actual mechanisms are still poorly understood. Its pathogenesis is still under discussion and the main hypotheses rely on heredity, embryology, metaplasia, trauma, and degenerative transformation. [16, 17] Another debated point on the stylohyoid complex is related to the pattern of calcification of the styloid process and stylohyoid ligament. Despite numerous studies classifying the location of calcification and ossification, there is still insufficient data in the literature regarding the relationship between the increase in the calcification of ligament and bone metabolism and processes of individuals. Hence, the aims to identify and illustrate new etiopathologic pathways that choreograph this disease should be among the top priorities in this field. 


\subsection{Diagnosis and Radiographic Evaluation}

Diagnosis is the pillar of any medical treatment. Without a proper diagnosis, the treatment success is impeded. A sound clinical knowledge of the condition makes diagnosis easier, and avoids unnecessary intervention of multiple medical specialities. As a rule, the workup of patients with suspected eagle's syndrome should include a detailed medical history, as well as a thorough head and neck examination to rule out other diagnoses. Attempts should be made to reinitiate the symptoms by manual manipulation over the stylohyoid complex cautiously. This can localize the pain trigger point while the patient performs cervical and oral movements. Palpation of the tonsillar fossa may reveal the tip of the styloid process as a hard bony spicule that aggravates symptoms with local tenderness. [18] Transpharyngeal palpation ascertains the presence of a bony projection and gives rise to the characteristic Eagle's pain. Some authors also suggest confirming the diagnosis with infiltration of local anesthetics into the tonsillar bed in order to alleviate pain. This procedure can be beneficial to some extent, but it may not differentiate Eagle's syndrome due to an elongated styloid process from other pathologic conditions, such as glossopharyngeal neuralgia. $[19,20]$

With classic presentations of eagle's syndrome, radiograph is not imperative for diagnosis. However, sometimes in case of misleading clinical presentation and missing physical findings, imaging can be very helpful in diagnosing a clinical suspicion of Eagle's syndrome. Radiographic evaluation is the ultimate step to confirm diagnosis and subsequently precedes the treatment required. Different types of imaging have been used to diagnosis Eagle's syndrome which include panoramic radiograph, lateral head and neck radiographs, Towne's radiographs, lateral oblique radiograph of mandible, antero-posterior head radiograph and computed tomography. However, it is mandatory for practitioners to be aware of the type of elongation and calcification of each styloid in order to describe its radiographic appearance. Hence, to better understand the radiographic findings, Langlais et al. [21] had classified radiologic appearance of styloid process based on the type of elongation and calcification. (Fig 2-3)

In some cases, lateral neck view is enough to confirm the diagnosis. Nonetheless, the advantage that modified Towne's view and orthopantomogram (OPG) have on it is that the entire length of the process can be seen very acutely and hence its deviation can be made out clearly [22] However, sometimes superimpositions of anatomical structures often hamper the visual clarity of the process. [23] A CT scan usually allows for the precise measurement of the styloid process length, direction, and anatomic variance and a three-dimensional (3D) volume-rendering CT scan add value to the modern diagnostic methods. [24, 25] Three-dimensional CT is considered by most to be the radiologic test of choice for diagnosis of Eagle's syndrome because it is the most advanced technique available to accurately measure the length of the styloid process and hyoid bone. [20]
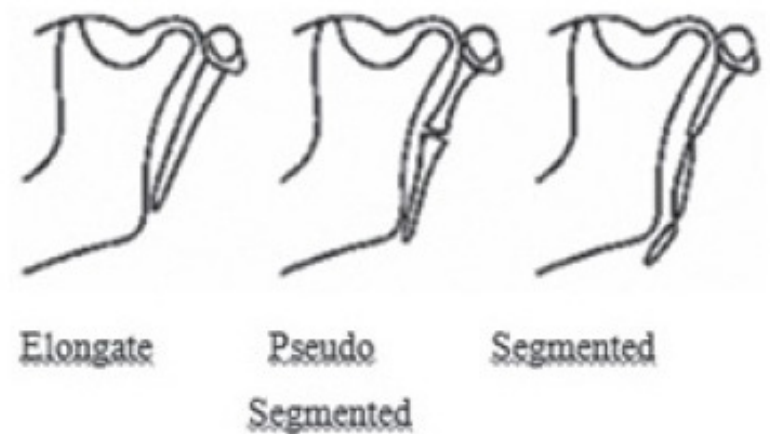

Figure 2. The morphological classification as proposed by Langlais in 1986

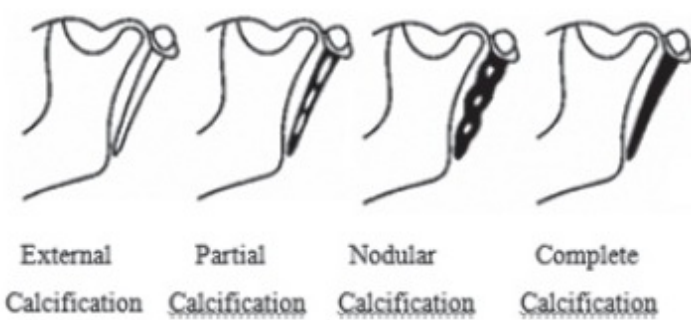

Figure 3. The classification according to calcification proposed by Langlais (1986)

\section{Differential Diagnosis}

It is mentioned by previous authors that due to its vagueness in symptoms, many patients have been treated for multiple different problems by different specialists, including dentists, neurologists, gastroenterologists, and even psychiatrists. Hence, awareness of the differential diagnosis of Eagle's syndrome helps in handling the cases in a more professional manner. Several pathogenetic factors should be taken into consideration before establishing a differential diagnosis, to rule out symptoms that might depend on anatomical regions adjacent to the styloid process and could mislead diagnosis. In particular the following pathogenic events should be considered: traumatic fractures of the apophysis, pharyngeal infections, rheumatoid processes of the hyoid apparatus, inflammation of the styloid muscle, TMJ dysfunction, atypical migraine, otitis media, degenerative and inflammatory changes inducing carotid veins rubbing and irritation of the anterior sympathetic nerves, formation of scars in the pharynx following tonsillectomy and pathologies of the third molars. $[15,18$, 26] The differential diagnosis should include but is not limited to, head and neck pain syndrome like glossopharyngeal neuralgia, fibromyalgia and trigeminal neuralgia. [26] ES should be kept in the differential diagnosis whenever examining a patient with persistent lateral neck, throat, or sub-mandibular pain that shows no other clinical findings. $[15,18]$ The different diagnosis of Eagle's syndrome is better appreciated in table 1. 
Table 1. Shows the differential diagnosis of Eagle's syndrome which may help the clinicians in practice

\begin{tabular}{|c|c|c|c|c|}
\hline & Eagle's syndrome & $\begin{array}{l}\text { Pulpitis } \\
\text { (Tooth pain) }\end{array}$ & $\begin{array}{c}\text { Idiopathic } \\
\text { trigeminal } \\
\text { neuralgia } \\
\end{array}$ & $\begin{array}{l}\text { Temporo-mandibular } \\
\text { disorder }\end{array}$ \\
\hline Type of pain & Dull & throbbing & Current like pain & Dull stabbing \\
\hline Intensity of pain & Medium & Slight to severe & Severe & Moderate \\
\hline Duration of pain & $\begin{array}{l}\text { Short (especially upon } \\
\text { moving head) }\end{array}$ & Can be upto hours & Seconds & minutes to hours \\
\hline $\begin{array}{l}\text { Characteristic } \\
\text { features }\end{array}$ & $\begin{array}{l}\text { Dysphagia, pain upon head } \\
\text { movement, pain in neck, } \\
\text { throat, floor of mouth, ear }\end{array}$ & $\begin{array}{c}\text { Sharp/ instantaneous, cold or } \\
\text { hot, nocturnal/diurnal } \\
\text { sensitivity }\end{array}$ & Trigger zone & $\begin{array}{l}\mathrm{TMJ} / \text { Muscle pain, } \\
\text { inability to open mouth, } \\
\text { pain during mastication }\end{array}$ \\
\hline Local treatment & $\begin{array}{l}\text { corticoid injection } \\
\text { Surgery- I. External approach, } \\
\text { II. Internal approach }\end{array}$ & $\begin{array}{c}\text { Dental treatment usually root } \\
\text { canal therapy. Pain may subside } \\
\text { upon injection of local } \\
\text { anaesthesia } \\
\end{array}$ & & $\begin{array}{l}\text { Physical therapy, splints, } \\
\text { anaesthetic injection }\end{array}$ \\
\hline General treatment & NSAIDs & NSAIDs & Anti convulsants & NSAIDs \\
\hline
\end{tabular}

\subsection{Treatment Modalities}

Once diagnosis is established, the mode of treatment can easily be chosen. Eagle's syndrome can be treated either medically or surgically. In medical therapy, oral medication like non-steroidal anti- inflammatory drugs (NSAIDS) with antidepressants and anticonvulsants can be given. Several alternative conservative methods such as transpharyngeal infiltration of steroid or local anesthetics have been used on the tonsil or tender areas, but with no remarkable outcome. [27] Other attempts to reduce pain were by physical therapy, relaxing the muscles that had been constricted due to styloid process stimulation.

Surgical intervention aimed at the pathologic point along the stylohyoid complex is the mainstay of treatment. Normally styloidectomy is the most favorable method. In the available literature, two approaches were discussed for carrying out the styloidectomy operation: (1) intraoral approach via tonsillar fossa; (2) extra oral approach from the neck. The external approach is favoured by N. Asherson (1957) and Moffat et al. (1977) and the intraoral approach via tonsillar fossa is advocated by Eagle (1949) [28]. Both approaches are suitable to manage Eagle's syndrome, depending upon the surgeon skills and convenience. It has been accepted that intraoral approach is advised only if distal tip of styloid process can be palpated in tonsillar fossa [29]. Some advantages of intraoral approach include simple procedure with less operative time, no external scar formation and disadvantages are inadequate visibility of surgical field, possible injury of nearby neurovascular structures, and risk of deep neck space infection. The main advantages of extra-oral approach are better visualization of surgical field and disadvantages are time consuming, external scar formation, and risk of facial nerve injury. The mode of surgery depends upon the surgeon's skills, type of cases and the patient's compliance.

\section{Conclusions}

It is important to note that Eagle's syndrome is a rare clinical entity that can disguise as typical medical conditions such as migraines, otitis, TMD, and nonspecific pain syndromes. It still remains a special diagnostic and therapeutic challenge due to its extraordinary nature. Most practitioners rarely come across with this rare condition. Thus, since they lack experience in this diagnosis, they ultimately attribute the symptoms to other causes. The occurrence of similar signs in diseases other than Eagle's syndrome may make a precise diagnosis difficult and time-consuming for many clinicians. It is also true that the characteristics findings can sometimes be incognito, but if a practitioner kept Eagle's syndrome in the differential diagnosis, it can be easily ruled in or ruled out by physical exam and, if required, by radiographic analysis.

\section{Author's Contributions}

Both Dr Daminee Chickooree and Dr Vahsish Ram contribute equally for the paper, hence both are co- authors.

\section{REFERENCES}

[1] Temporomandibular disorder or Eagle's syndrome? A clinical report. Ferreira de Albuquerque R Jr, Müller K, Hotta TH, Gonçalves M. J Prosthet Dent. 2003 Oct; 90(4):317-20.

[2] De Souza Carvalho AC, Magro Filho O, Garcia IR, Jr, et al. Intraoral approach for surgical treatment of Eagle syndrome. Br J Oral Maxillofac Surg 2009;47:153-154.

[3] Todo T, Alexander M, Stokol C, et al. Eagle syndrome revisited: cerebrovascular complications. Ann Vasc Surg 2012; 26:729e1-5.

[4] Chuang WC, Short JH, McKinney AM, et al. Reversible left hemispheric ischemia secondary to carotid compression in Eagle syndrome: surgical and CT angiographic correlation. Am J Neuroradiol. 2007;28:143-145.

[5] Eagle WW. Elongated styloid process. Report of two cases. Arch Otolaryngol. 1937;25:584- 587. 
[6] Eagle WW. Elongated styloid process. Further observations and a new syndrome. Archives of Otolaryngology. 1948; 47(5): 630-640.

[7] Murtagh RD, Caracciolo JT, Fernandez G.CT findings associated with Eagle syndrome. AJNR Am J Neuroradiol. 2001 Aug;22(7):1401-2.

[8] Holloway $\mathrm{M}$ et al. A pediatric case of Eagle's sndrome AJDC 1991; 145:339-40.

[9] Balcioglu HA, Kilic C, Akyol M, Ozan H, Kokten G. Length of the styloid process and anatomical implications for Eagle's syndrome. Folia Morphol (Warsz) 2009;68:265-70.

[10] R Sudhakara Reddy, Ch Sai Kiran, N. Sai Madhavi, M N. Raghavendra, A. Satish. Prevalence of elongation and calcification patterns of elongated styloid process in south India. J Clin Exp Dent. Feb 2013; 5(1): e30-e35.

[11] Woolery W.A. The diagnostic challenge of styloid elongation (Eagle's syndrome) J. Am. Osteopath. Assoc. 1990;90:88-89.

[12] Hollinshead WH: Anatomy for surgeons - The head and neck. Philadelphia, JB Lippincott Co,1982.

[13] Chaurasia BD; Styloid apparatus - deep structures in the neck. In: Chaurasia BD, editor. Human anatomy, regional and applied dissection and clinical. Volume 3, Head, neck and brain. New Delhi: CBS Publishers; 2004 12. Soames RW. Skeletal system. In: Williams PL, editor. Gray's anatomy. 38. New York: Churchill Livingstone; 1995. p. 592.

[14] Pierrakou ED. Review Eagle's syndrome. Review of the literature and a case report. Ann Dent. 1990 Summer; 49(1):30-3.

[15] Farhat HIElhammady MSZiayee HAziz-Sultan MAHeros RC Eagle syndrome as a cause of transient ischemic attacks. J Neurosurg 2009;110 (1) 90- 93.

[16] Klécha A, Hafian H, Devauchelle B, et al. A report of post-traumatic Eagle's syndrome. Int J Oral Maxillofac Surg 2008;37:970-972.

[17] Koivumäki A, Marinescu-Gava M, Järnstedt J, et al. Trauma induced eagle syndrome. Int $\mathrm{J}$ Oral Maxillofac Surg 2012;41:350-353.

[18] Candice C. Colby, MD; John M. Del Gaudio, MD. Stylohyoid Complex Syndrome A New Diagnostic Classification. Arch Otolaryngol Head Neck Surg. 2011;137(3):248-252.
[19] Van der Westhuijzen AJvan der Merwe JGrotepass FW Eagle's syndrome: lesser cornu amputation: an alternative surgical solution? Int J Oral Maxillofac Surg 1999;28 (5) 335337.

[20] Beder EOzgursoy OBKaratayli Ozgursoy S Current diagnosis and transoral surgical treatment of Eagle's syndrome. J Oral Maxillofac Surg 2005;63 (12) 1742-1745.

[21] Langlais RP, Miles DA, Dis ML; Elongated and mineralized stylohyoid ligament complex: a proposed classification and report of a case of Eagle's syndrome. Oral Surg Oral Med Oral Pathol. 1986;61:527-532.

[22] Rezui-Marhoul L, Douira W, Saïd W, et al. Le syndrome de Eagle: à propos d'un cas. Rev Stomatol Chir Maxillofac 2004;105:50-52.

[23] Savranlar A, Uzun L, Ugur MB, et al. Three-dimensional CT of Eagle's syndrome. Diagn Interv Radiol 2005;11:206-209.

[24] Valerio CS, Peyneau PD, de Sousa AC, Cardoso FO, de Oliveira DR, Taitson PF, et al. Stylohyoid syndrome: surgical approach. J Craniofac Surg. 2012;23:e138-e140.

[25] Dao A, Karnezis S, Lane JS, 3rd, et al. Eagle syndrome presenting with external carotid artery pseudoaneurysm. Emerg Radiol 2011;18:263-265.

[26] Mendelsohn AH, Berke GS, Chhetri DK. Heterogeneity in the Clinical Presentation of Eagle's Syndrome. Otolaryngol Head Neck Surg. 2006 Mar; 134(3):389-93.

[27] Ceylan A, Köybasioglu A, Celenk F, et al. Surgical treatment of elongated styloid process: Experience of 61 cases. Skull Base 2008;18:289-295.

[28] Y. K. Maru, Kusum Patidar; Stylalgia and its surgical management by intra oral route - clinical experience of 332 cases; Indian J Otolaryngol Head Neck Surg. 2003 April; 55(2): $87-90$.

[29] 29.L.H. Diamond, D.A. Cottrell, M.J. Hunter, M. Papageorge; Eagle's syndrome: a report of 4 patients treated using a modified extraoral approach.J Oral Maxillofac Surg, 59 (12) (2001), pp. 1420-1426.

[30] Chase DC, Zarmen A, Bigelow WC, McCoy JM; Eagle's syndrome: a comparison of intraoral versus extraoral surgical approaches. Oral Surg Oral Med Oral Pathol. 1986;62:625629. 